\title{
MERITOCRACIA NA VISÃO DA EDUCAÇÃO E DA ADMINISTRAÇÃO: UMA DISCUSSÃO POSSÍVEL
}

\section{MERITOCRACY IN THE VIEW OF EDUCATION AND ADMINISTRATION: A POSSIBLE DISCUSSION}

\author{
Marcelo Almeida de Camargo Pereira ${ }^{1}$ \\ Rita de Cássia da Rosa Sampaio Brochier ${ }^{2}$ \\ Vera Lucia Felicetti ${ }^{3}$
}

\section{Resumo}

Na educação, a meritocracia é pensada como igualdade quando a abordagem é voltada ao aluno, e ao professor é pensada como valorização. Sob o olhar da administração a meritocracia é uma forma de reconhecimento, promoção e legitimação. $\mathrm{O}$ artigo tem como objetivo discutir a meritocracia na visão da Educação e da Administração. A bibliografia evidencia que o mérito decorre do valor do empenho do indivíduo através de sua atuação, onde estes são avaliados e os melhores, reconhecidos. Ao final, percebese o trabalho meritocrático com naturalidade na administração e com resistência na educação.

Palavras-chave: Ensino Superior. Meritocracia. Educação. Administração. Valorização do Professor.

\begin{abstract}
In education, meritocracy is seen as equality when the approach is based on the student, and to the teacher it is seen as recognition and value. In the business field, meritocracy is seen as a form of recognition, promotion and legitimation. This paper aims to discuss meritocracy both in the prisms of Education and Business. The literature shows that meritocracy is the result of one's efforts in their performance in multiple, one is evaluated and the best ones, recognized. In the end, it was noted that meritocratic work is so natural in business and facing resistance in education.
\end{abstract}

Key-words: Higher education. Meritocracy. Education. Business. Teacher Valuation.

\footnotetext{
1 Mestre e Doutorando em Educação pela Universidade La Salle em Canoas, RS. Bacharel em Administração de Empresas. Endereço: Av. Alegrete, 144/702, Porto Alegre, RS - E-mail: marceloacpereira@gmail.com.

2 Mestra em Educação e Doutoranda em Memória Social e Bens Culturais pela Universidade La Salle em Canoas, RS e Bacharela em Administração de Empresas. Endereço: BR 386, km 411 s/no Bairro Vendinha, Montenegro, RS - E-mail: ritadecassi.brochier@gmail.com.br

3 Doutora em Educação pela PUCRS (RS, Brasil) e Integrante do Programa de Pesquisa Conjunta CAPES/PUCRS/Universidade do Texas (Estados Unidos). Professora do Doutorado em Educação da Universidade La Salle. E-mail: verafelicetti@ig.com.br
} 


\section{INTRODUÇÃO}

A recente decisão da Universidade Federal de Santa Maria - UFSM de extinguir o vestibular para ingresso na Instituição gerou polêmica e discussões. A partir de tal decisão, os candidatos a ingressarem na Universidade utilizarão apenas a nota do $\mathrm{ENEM}^{4}$ - no $\mathrm{SISU}^{5}$, sendo ainda que $50 \%$ das vagas na UFSM são destinadas a cotistas. $\mathrm{O}$ assunto gerou tamanha polêmica que a Justiça Federal suspendeu a decisão do $\mathrm{CEPE}^{6}$, pelo menos para este ano de 2014. Esta tentativa de mudança no sistema de ingresso na UFSM demonstra a prática meritocrática no sistema de seleção. É necessário estar entre os melhores no ENEM, onde a seleção é nacional e torna-se necessário estar entre os melhores no processo de seleção do SISU. A exemplo, isto já acontece no sistema de seleção do ProUni ${ }^{7}$, cujo objetivo é conceder bolsas de estudos para o Ensino Superior em instituições de ensino privado.

A meritocracia é assunto ainda mais habitual no âmbito da administração. Nas empresas a meritocracia é uma forma de reconhecimento, promoção e legitimação de desempenhos no mundo competitivo do trabalho. Esta forma de avaliação, no entanto, parte de um princípio igualitário onde o mérito pessoal, proveniente das ferramentas do indivíduo como experiência, vontade, competências, trabalho e resultados, promove o indivíduo a outros níveis profissionais, seja através da promoção pessoal ou financeira.

E na educação pode-se contemplar a meritocracia pensando na igualdade referindo-se ao aluno ou na valorização referindo-se ao professor. A meritocracia não é um assunto "novo", mas talvez, pouco discutido, principalmente no Brasil na área educacional. Segundo Valle e Ruschel (2010) desde 1970 o tema está se potencializando e o sistema nacional de educação baseando-se em características meritocráticas para reavaliar competências, se burocratizar, e estender as condições de ações. Reconhecendo a importância desta temática, o objetivo deste trabalho é discutir a meritocracia na visão da Educação e da Administração. Para tal, o artigo está estruturado da seguinte forma: primeiramente uma revisão de literatura sobre a meritocracia sob o olhar da educação e, na sequência, uma revisão de literatura sobre o tema sob o olhar da administração. Em seguida, sob o título "Uma discussão possível",

\footnotetext{
${ }^{4}$ ENEM - Exame Nacional do Ensino Médio

${ }^{5}$ SISU - Sistema de Seleção Unificado

${ }^{6} \mathrm{CEPE}$ - Conselho de Ensino Pesquisa e Extensão

${ }^{7}$ ProUni - Programa Universidade para Todos
} 
serão apresentadas as diferenças e semelhanças da meritocracia nos dois ambientes, educação e administração. Por fim, as considerações finais e as referências usadas do trabalho.

\section{MERITOCRACIA: uma abordagem sob o olhar da Educação}

Nesta parte, será abordada a meritocracia sob o olhar da Educação com um enfoque geral na área. Como ponto de partida, cabe aqui, inicialmente a definição da palavra mérito: "merecimento, aptidão, superioridade, valor moral ou intelectual". E meritocracia, num contexto sociológico: "forma de liderança que se baseia no mérito, nas capacidades e nas realizações alcançadas” PRIBERAM DICIONÁRIO ON LINE, 2014). Valle e Ruschel (2010) destacam as expressões: "ter mérito" e "quem é merecedor". Ter mérito supõe ser digno de recompensa, elogio, prêmio, estima, apreço. "É merecedor quem tem valor, quem apresenta um conjunto de qualidades intelectuais e morais reconhecidas (capacidade, habilidade, inteligência, talento, aptidão, dom, vocação) e tudo faz para ser digno delas" (VALE E RUSCHEL, 2010, p.76).

Em se tratando de educação pode-se contemplar a meritocracia pensando na igualdade referindo-se ao aluno ou na valorização referindo-se ao professor. Em ambos os casos, a Constituição da República Federativa do Brasil de 1988, cita no Art. 205 a educação como direito de todos e no Art. 206 sobre a valorização dos profissionais da educação como um dos princípios norteadores para tal direito:

Art. 205. A educação, direito de todos e dever do Estado e da família, será promovida e incentivada com a colaboração da sociedade, visando ao pleno desenvolvimento da pessoa, seu preparo para o exercício da cidadania e sua qualificação para o trabalho.

Art. 206. O ensino será ministrado com base nos seguintes princípios:

I - igualdade de condições para o acesso e permanência na escola;

II - liberdade de aprender, ensinar, pesquisar e divulgar o pensamento, a arte e o saber;

III - pluralismo de ideias e de concepções pedagógicas, e coexistência de instituições públicas e privadas de ensino;

IV - gratuidade do ensino público em estabelecimentos oficiais;

V - valorização dos profissionais da educação escolar, garantidos, na forma da lei, planos de carreira, com ingresso exclusivamente por concurso público de provas e títulos, aos das redes públicas; [...] (BRASIL, 1988, grifo nosso).

Revista de Administração Educacional, Recife, V. 1. No 2 - jul/dez. 2017 p. 71-87 
Dessa forma, percebe-se que a meritocracia, mesmo que indiretamente, vem permeando o contexto da Educação. Valle e Ruschel (2010), demonstram em seus estudos que a meritocracia na Educação começou a ser citada já na Constituição Federal de 1934, bem como nas Constituições 1937, 1946, 1967 e 1988. As autoras observam que o termo mérito aparece nos textos legais destas constituições através de "palavras correlatas indicando que a intenção meritocrática se faz presente na política educacional brasileira desde o momento em que se idealizou um sistema nacional de educação" (VALLE E RUSCHEL, 2010, p.82). As autoras concluem que "os avanços em termos de ampliação das oportunidades escolares são evidentes na Constituição Federal de 1988, aprovada num contexto de grandes demandas por democratização da sociedade em todas as suas dimensões" (VALLE E RUSCHEL, 2010, p.82).

Segundo Dubet (2004), a igualdade de oportunidades requer igualdade de acesso, é onde a meritocracia se insere. Para o mesmo autor, a escola se torna mais justa no momento em que permite que todos os alunos entrem na competição, independente de categoria social. Nesse aspecto, podemos fazer uso do estudo de Felicetti e Morosini (2009) as quais apontam que fatores como sexo, raça, condições socioeconômicas, idade ou deficiências não podem ser fatores decisivos para a inserção no Ensino Superior. As autoras concluem que o comprometimento individual dos indivíduos torna-se fator para a equidade e igualdade de oportunidades, onde o primeiro está relacionado à aquisição de habilidades e esforços dos indivíduos e o segundo tange às oportunidades de acesso ao ensino.

Também a Lei de Diretrizes e Bases (LDB) da Educação, Lei no 9.394, de 20 de dezembro de 1996, cita em seu art. 67 a valorização do profissional da educação:

Art. 67: Os sistemas de ensino promoverão a valorização dos profissionais da educação, assegurando-lhes, inclusive nos termos dos estatutos e dos planos de carreira do magistério público:

I - ingresso exclusivamente por concurso público de provas e títulos;

II - aperfeiçoamento profissional continuado, inclusive com licenciamento periódico remunerado para esse fim;

III - piso salarial profissional;

IV - progressão funcional baseada na titulação ou habilitação, e na avaliação do desempenho;

V - período reservado a estudos, planejamento e avaliação, incluído na carga de trabalho;

VI - condições adequadas de trabalho (LBD, 1996, p. 23, grifo nosso). 
O artigo 67 da LDB destaca a valorização dos profissionais da educação, bem como, descreve como deve ser feita. Já no inciso I menciona-se o mérito, cujo ingresso ao magistério público deve acontecer via concurso público e prova de títulos, ou seja, quem tiver o melhor desempenho. O inciso IV fala da progressão profissional, que também acontece com prova de títulos e avaliação de desempenho dos profissionais, onde o mérito surge mais uma vez como fator de seleção, neste caso, de progressão no magistério público.

Para Barbosa (2003) a meritocracia é "um conjunto de valores que postula que as posições dos indivíduos na sociedade devem ser consequência do mérito de cada um" (BARBOSA, 2003, p.22). Assim, a posição de um indivíduo na sociedade decorre do resultado de seu mérito. Segundo a autora, a meritocracia pode ser entendida em duas dimensões, a afirmativa e a negativa. A primeira atribui valores as variáveis sociais e a segunda não. Na dimensão negativa, a meritocracia não confere importância a variáveis sociais como origem, posição social, poder político ou econômico na disputa de algo ou alguma coisa de direito. Enquanto a dimensão afirmativa leva em conta todas estas variáveis e as avalia como parte do processo.

Dubet (2004), por sua vez, traz a concepção de meritocracia através do seu resgate histórico. Até a década de 60, o nascimento ainda era o principal fator determinante no processo educacional, uma vez que o acesso nas melhores escolas era para pessoas da aristocracia. Para esse autor, “o mérito desempenhava um papel apenas marginal para os filhos dos trabalhadores 'dotados' que podiam, graças ao sistema de bolsas." (DUBET, 2004, p. 541).

Esse sistema, em realidade tratava-se de um mérito parcial, dedicado a promover mobilidade social às classes médias. Para Dubet (2004), em uma sociedade democrática, o mérito pessoal é a única forma de se construir “desigualdades justas" (2004, p. 544), legitimadas, uma vez que as geradas via aristocrática não são mais moralmente aceitáveis.

Entende-se aqui, como conceito de meritocracia o conjunto de valores pessoais que agregam ao indivíduo no âmbito social, moral e intelectual, superioridade em termos competitivos, associados ao esforço e às habilidades pessoais de cada um.

Essa concepção de meritocracia pode ser trazida ao contexto do Ensino Superior, apresentando uma série de questionamentos e dificuldades apontados por Dubet (2004), os quais são resumidos abaixo: 
- A promoção da competição escolar por si só não elimina as desigualdades nas categorias sociais, entre os sexos e as vantagens aos mais favorecidos, ou seja, “as desigualdades sociais pesam muito nas desigualdades escolares" (DUBET, 2004, p.542).

- A igualdade pressupõe uma oferta escolar e acadêmica igual e objetiva, independente da classe social. Mas no modelo meritocrático, a concorrência não é totalmente justa.

- O modelo meritocrático gera os "vencidos" (aqueles que não conseguiram competir ou ficaram abaixo dos resultados). Como tratar esse grupo? A meritocracia não estaria legitimando as desigualdades? A meritocracia, nestes casos, os responsabiliza pelo fracasso, já que tiveram as mesmas oportunidades que outros e não obtiveram sucesso.

- Do ponto de vista pedagógico, para os alunos se envolverem em uma mesma competição, eles precisam ser submetidos às mesmas provas. Mesmo que os princípios da competição sejam justos, o modelo meritocrático promove grandes desigualdades entre os alunos bons e menos bons.

- Como balancear o mérito com nossos dons e aptidões? É possível medir o mérito? Ele existe?

Com base nesse item apresentado, podemos verificar o conceito de meritocracia atrelado ao resultado do esforço pessoal do indivíduo (alunos e professores) decorrentes de seu empenho e desempenho. Este esforço, medido e quantificado, gera mais valia pessoal e também profissional, via reconhecimento, nota ou outra forma de gratificação, porém deve ocorrer em um ambiente que preconize a igualdade de oportunidades para uma avaliação eficaz do mérito.

\section{MERITOCRACIA: uma abordagem sob o olhar da Administração}

Para que seja possível abordar o tema meritocracia sob a ótica da Administração, convém inicialmente traçarmos o ambiente no qual este conceito se insere.

O mercado de trabalho tem sofrido mudanças desde a Revolução Industrial. O trabalho, antes manual e ligado ao trabalhador, hoje se tornou abstrato e com diversas relações de competição resultantes do sistema capitalista vigente. Chiavenato (2010) 
destaca que, apesar da modernização do trabalho que teve como grande vantagem os melhores empregos e salários, a desvantagem desse modelo é a precarização do trabalho e renda dos que não se atualizaram ou não tiveram oportunidades de atualização tecnológica e formação.

A tecnologia, por sua vez, detém lugar de destaque no tema. Dentre o debate acerca do papel da tecnologia no trabalho, há argumentos que apontam que esta é inimiga do emprego, enquanto outros entendem que a inovação tecnológica e a melhoria da produtividade expandem os níveis de emprego. Essa expansão, no entanto, faz com que seja necessário um processo de destruição criativa, isto é, a inovação e novas práticas que conduzem à obsolescência programada de produtos e serviços (CHIAVENATO, 2010).

Ainda para Chiavenato (2010), a demanda por trabalhadores de baixa qualificação (os excluídos da atualização tecnológica e da formação) se extinguirá, por isso, os jovens devem buscar na educação e na qualificação seu futuro profissional.

Podemos inserir no contexto apresentado, as competências como fator de empregabilidade. No âmbito da administração, o conceito de competência para Rocha Neto (2003) "compreende o saber atuar com responsabilidade, mobilizando/integrando recursos, inclusive conhecimentos, no sentido de aprender a aprender, com o propósito de agregar valores aos indivíduos e às organizações.” (ROCHA NETO, 2003, p. 22, itálico do original).

Com isso, ao pensarmos no profissional competente, aquele que mobiliza conhecimentos, aprende e aplica as novas tecnologias e gera resultados para as organizações nas quais atua, não tem garantida a sua atuação no mercado de trabalho, tampouco seu emprego, mas está apto na disputa por colocação dentro do ambiente competitivo.

As organizações, por outro lado, tem o desafio de administrar as competências dos seus funcionários, além de gerir as múltiplas relações de mercado nas quais atuam, como a concorrência, as ameaças, as oportunidades, de forma a garantir o contínuo da empresa. A atração e a manutenção de talentos e profissionais qualificados requerem formas de remuneração flexíveis. Existem muitas formas de remunerar os empregados, sendo que esse processo é complexo e associa o valor do trabalho ao resultado esperado da organização, assim como perante a comparação com o mercado de trabalho em si (ROBBINS; JUDGE e SOBRAL, 2010). 
Apesar de serem oriundos da área de Administração, estes últimos autores trazem um exemplo interessante da área de Educação:

"Para que eu faria um esforço extra em meu trabalho?", pergunta Ana Garcia, professora de ensino fundamental em uma escola de Cuiabá, no Mato Grosso. "Posso me esforçar ou apenas fazer o mínimo necessário. Não faz a menor diferença. Eu recebo o mesmo salário. Por que eu faria qualquer coisa além do mínimo exigido?" (ROBBINS, JUDGE e SOBRAL, 2010, p. 243, aspas do original).

Este exemplo abordado pelos autores reforça a questão complexa da definição da remuneração individual com base em competências e / ou resultados, que permeia tanto as organizações privadas, assim como as públicas de diversas esferas. Na esfera pública, algumas mudanças foram implementadas, com planos de remuneração variável baseados em tempo de carreira ou através de desempenho individual, por base no mérito. A fala da professora pode ser identificada que não há qualquer reconhecimento em sua atuação, não há em suas palavras, 'a menor diferença'.

O pagamento com base no mérito, ou por desempenho individual, está diretamente atrelado ao desempenho do indivíduo, por base em escalas de avaliação. Essas escalas, por sua vez, comparam os que possuem melhor e pior desempenho. Empresas japonesas, através de uma pesquisa realizada na década de 90, apontam que o sistema de remuneração por mérito é um meio importante para o alcance de metas da administração, como forma também de gerir e reter profissionais (ROBBINS, JUDGE e SOBRAL, 2010).

O contraponto, partindo dos mesmos autores, está no fato de que as avaliações ficam restritas aos anos nos quais se avaliam estatisticamente, assim como no fato de que o fundo para aumentos salariais está condicionado mais à economia que no percentual de desempenho dos indivíduos. O corporativismo sindical também tem sido um fator de resistência a esta forma de remuneração, prevalecendo ainda o plano de carreira por tempo de serviço no serviço público.

Um ponto interessante que pode auxiliar na explicação do corporativismo é apontado por Barbosa (1996), ao afirmar que:

Do ponto de vista histórico, a política de avaliar as pessoas e suas respectivas produções como um procedimento administrativo regular no interior das organizações começa mais ou menos junto com a revolução nas relações de trabalho trazida por Frederik Taylor. 
Quando, no início da revolução da produtividade trazida pela administração científica, Taylor sugeriu a aplicação de seu método de eficiência à administração de pessoal, ninguém imaginou na época a grande quantidade de problemas que estava surgindo. Uma coisa é medir a eficiência de máquinas e linhas de produção, que podem ser objetivamente medidas. Outra é julgar, comparar, avaliar e medir as produções humanas, que possuem características difíceis de serem objetivamente avaliadas (BARBOSA, 1996, p. 60-61).

Esta avaliação trazida por Barbosa (1996) remete ao questionamento de como se avaliar, ou colocar em estatísticas o processo de ensino e aprendizagem com o olhar da administração. A mesma autora ressalta que, apesar da avaliação de desempenho ainda ser uma grande fonte de promoção de crescimento profissional, ela também é de atritos, insatisfações e frustrações para quem a concebe e aplica, além dos indivíduos alvo de sua aplicação.

Barbosa (1996) avalia que os dilemas desta forma de avaliação têm sido atribuídos aos instrumentos de avaliação e aos avaliadores. Com isso, o objetivo seria encontrar um sistema que pudesse neutralizar a subjetividade do avaliador, supondo-se na existência de uma realidade concreta e objetiva que pudesse ser captada em sua dimensão concreta.

Um ponto de fundamental importância destacado por Barbosa (1996) tange em relação à igualdade e ao desempenho, que em um olhar superficial podem não ter relação. Em sociedades modernas, há o pressuposto de que todos nascem iguais e livres, porém com suas idiossincrasias, talentos, virtudes e sua individualidade. Contudo, para que o desempenho seja legítimo socialmente, este deve ser pautado em um contexto igualitário, onde as pessoas são avaliadas exclusivamente por suas realizações, independente do poder econômico, status e relações familiares.

Com base neste item, podemos perceber sob o olhar da Administração, que a meritocracia é uma forma de reconhecimento, promoção e legitimação de desempenhos no mundo competitivo do trabalho. Esta forma de avaliação, no entanto, parte de um princípio igualitário onde o mérito pessoal, proveniente das ferramentas do indivíduo como experiência, vontade, competências, trabalho e resultados, promove o indivíduo a outros níveis profissionais, seja através da promoção pessoal ou financeira.

\section{UMA DISCUSSÃO POSSÍVEL}


Visto os conceitos de meritocracia sob o olhar da Educação e da Administração, podemos verificar algumas semelhanças e diferenças em cada uma delas, as quais constam no quadro 1.

\section{Quadro 1 - O conceito de Meritocracia na Educação e na Administração}

\begin{tabular}{|c|c|}
\hline Educação & Administração \\
\hline \multicolumn{2}{|c|}{ Semelhanças } \\
\hline $\begin{array}{l}\text { - O mérito pressupõe recompensa, elogio, } \\
\text { prêmio a quem é reconhecido por suas } \\
\text { qualidades morais e intelectuais. }\end{array}$ & $\begin{array}{l}\text { - O mérito pressupõe reconhecimento, através do } \\
\text { crescimento profissional, pecúnia ou status, } \\
\text { decorrentes do valor agregado do seu trabalho } \\
\text { para as organizações. }\end{array}$ \\
\hline $\begin{array}{l}\text { - O conceito de meritocracia está inserido na } \\
\text { carta magna indiretamente através dos } \\
\text { princípios da igualdade e no ingresso via } \\
\text { concurso público de provas e títulos. }\end{array}$ & $\begin{array}{l}\text { - O conceito de meritocracia está associado às } \\
\text { regras de livre mercado e de concorrência, } \\
\text { amplamente relacionado às competências. }\end{array}$ \\
\hline $\begin{array}{l}\text { - Avaliação de desempenho pressupõe bases e } \\
\text { critérios de avaliação objetivos, que } \\
\text { desconsideram a subjetividade docente. } \\
\text { Questiona-se tal método. }\end{array}$ & $\begin{array}{l}\text { - Questiona-se como avaliar ou transformar em } \\
\text { estatísticas. Uma avaliação mal realizada pode } \\
\text { gerar insatisfação, atritos e frustrações. }\end{array}$ \\
\hline $\begin{array}{l}\text { - O sistema meritocrático se contrapõe ao } \\
\text { aristocrático. Mesmo gerando diferenças, ele } \\
\text { promove mobilidade de classes e legitima } \\
\text { algumas diferenças de forma mais justa. }\end{array}$ & $\begin{array}{l}\text { - Requer um contexto igualitário, onde todos } \\
\text { possam concorrer sem interferência de seu } \\
\text { poder econômico ou status social. }\end{array}$ \\
\hline \multicolumn{2}{|c|}{ Diferenças } \\
\hline $\begin{array}{l}\text { - O sistema meritocrático enfrenta } \\
\text { corporativismo e resistência por parte dos } \\
\text { professores. Atualmente utiliza-se o plano de } \\
\text { carreira por tempo de serviço como base para } \\
\text { remuneração. }\end{array}$ & $\begin{array}{l}\text { - É um caminho natural para as empresas que } \\
\text { desejam reter e promover talentos. }\end{array}$ \\
\hline $\begin{array}{l}\text { - Não há estímulo para trabalhar de forma } \\
\text { diferenciada, uma vez que não resulta em } \\
\text { diferença o seu reconhecimento. }\end{array}$ & $\begin{array}{l}\text { - Pessoas devem ser estimuladas através de } \\
\text { reconhecimento financeiro ou profissional. }\end{array}$ \\
\hline $\begin{array}{l}\text { - Preocupação com os vencidos (os que não } \\
\text { atingiram os resultados). }\end{array}$ & $\begin{array}{l}\text { - Preocupação com os resultados e solidez da } \\
\text { empresa. }\end{array}$ \\
\hline
\end{tabular}

Fonte: Elaborado pelos autores (2014).

Com base no quadro 1, podemos perceber que a concepção de meritocracia converge na compreensão de que o mérito decorre do valor do empenho do indivíduo através de sua atuação. A exemplo disso, podemos mencionar o aluno buscando uma vaga no vestibular ou no ProUni, e o professor buscando a sua valorização na sua avaliação por desempenho, ou no contexto da administração, onde o mérito pode definir a remuneração de um indivíduo, através do atingimento de metas. Ou seja em múltiplas 
esferas (profissionais, acadêmicas e estudantis), onde com base em parâmetros, os indivíduos são avaliados e os que têm melhor resultado são reconhecidos.

O contraste nas concepções ocorre na visão quanto à implantação do modelo meritocrático, onde na Educação enfrenta forte corporativismo e rejeição, enquanto na Administração é tida com naturalidade, dentro do seu contexto competitivo e liberal. Nota-se também a divergência em relação aos que não atingem as metas estabelecidas. $\mathrm{Na}$ Educação verifica-se o questionamento de como lidar com os "vencidos", enquanto no contexto da Administração essa questão não emerge, pois o foco é a retenção dos talentos para o crescimento das organizações.

Como base para exemplificação deste trabalho e para propiciar o debate em torno do tema meritocracia, utilizaremos dois grandes exemplos, um no âmbito escolar com conexões à Administração e outro relacionado ao acesso ao Ensino Superior.

\section{Exemplos em Questão}

O primeiro exemplo trata-se de uma recente política instituída no Estado de São Paulo, Projeto de Lei Complementar (PLC) 29/2009, que institui o Programa de Valorização pelo Mérito para professores, supervisores e diretores da rede estadual de ensino. “[...] os professores terão a chance de praticamente quadruplicar, ao longo da carreira, o salário inicial da carreira desde que cumpram as regras de promoção (assiduidade e tempo de permanência numa mesma escola) e consigam notas mínimas na prova de avaliação anual que será aplicada pela Secretaria de Estado da Educação" (SECRETARIA DA EDUCAÇÃO DO ESTADO DE SÃO PAULO, 2009).

Podemos vislumbrar o desafio da implantação da meritocracia como forma de remuneração dos professores. A proposta dessa secretaria pode até ser vista como a resposta ao questionamento da professora Ana Garcia, visto no item anterior, onde ela questiona o porquê de fazer diferente ou qual diferença faria se fizesse diferente, pois nada mudaria, não haveria reconhecimento, nesse caso financeiro. A meritocracia pode ser um grande instrumento tanto de remuneração profissional como para melhoria dos indicadores da educação brasileira.

Vale ressaltar que esta implantação deve ser cuidadosa em relação aos parâmetros, lembrando o que nos aponta Barbosa (1996) sobre como avaliar, julgar e comparar as produções humanas, que são constituídas de referencias nada fáceis de 
serem compreendidas, medidas, como, por exemplo, mensurar a competência produtiva de uma máquina em uma linha de produção através de um cálculo objetivo.

O segundo exemplo trata-se de uma Política Pública de acesso ao Ensino Superior, o Programa Universidade para Todos. São quase 10 anos desde a sua criação e institucionalização pela Lei $\mathrm{n}^{\circ} 11.096$ de 13 de janeiro de 2005. O Pro Uni "tem como finalidade a concessão de bolsas de estudo integrais e parciais em cursos de graduação e sequenciais de formação específica, em instituições de Ensino Superior privada" (Ministério da Educação - MEC, 2014).

Segundo informações do Ministério Educação - MEC (2014), desde a sua criação até o segundo semestre de 2013 mais de 1,9 milhões de estudantes já foram beneficiados com as bolsas integrais ou parciais que o programa oferece. Para a seleção das bolsas, o MEC utiliza um sistema informatizado, que segundo ele justifica a transparência e a segurança no processo seletivo. Podem beneficiar-se do programa os estudantes que concluíram o Ensino Médio em escola pública ou escola particular, se bolsista integral, e realizaram o Exame Nacional do Ensino Médio, já que é a nota do ENEM um dos critérios para o processo de seleção. O próprio ministério destaca que a seleção baseia-se na qualidade e no mérito do estudante que obteve o melhor desempenho acadêmico. O gráfico 1 apresenta o número total de bolsas (integrais e parciais) ofertadas até 2013 pelo programa:

\section{Gráfico 1: Bolsas Pro Uni Ofertadas por Ano}

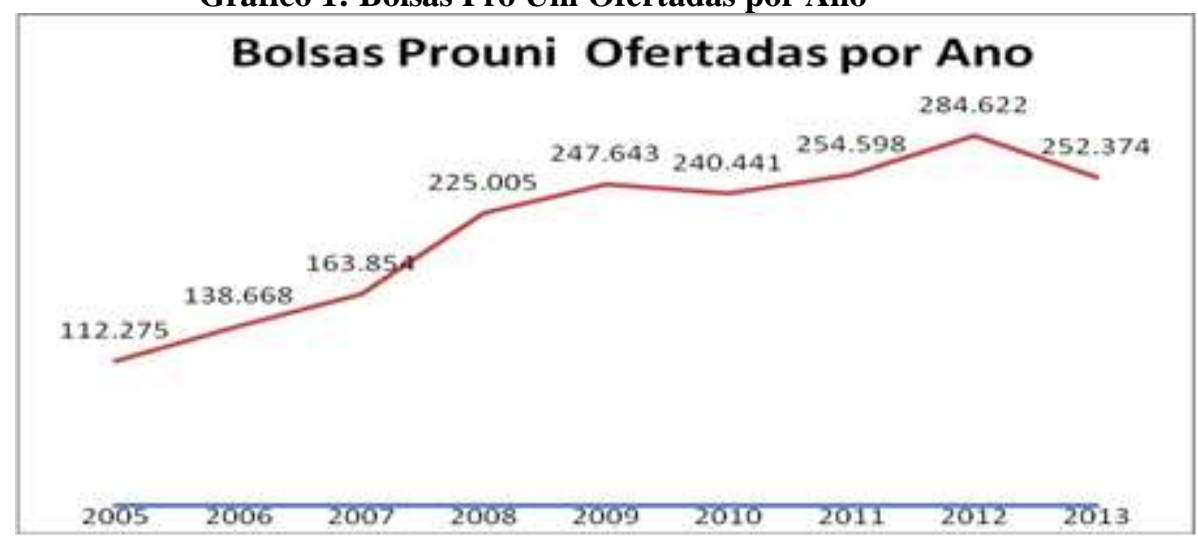

Fonte: Elaborado pelos autores com base em Portal Pro Uni, 2014.

O gráfico 1 demonstra a evolução do número total de bolsas ofertadas no Brasil. Já no primeiro ano mais de 100 mil bolsas foram oferecidas, percebendo-se um crescimento acentuado até 2009, com uma ligeira queda em 2010, logo recuperada em 
2011 e 2012. Em 2013, uma queda de aproximadamente 32.000 bolsas. No total mais de 1,9 milhões de bolsas já foram ofertadas.

Importante destacar que o número de bolsas ofertadas é o número de inscritos em cada processo seletivo. A tabela 1 apresenta a relação de inscritos e as bolsas ofertadas:

Tabela 1: Relação de Inscritos e Bolsas Ofertadas

\begin{tabular}{cccc}
\hline ANO & $\mathbf{N}^{\mathbf{0}}$ DE INSCRITOS & $\mathbf{N}^{\mathbf{0}}$ BOLSAS OFERTADAS & $\begin{array}{c}\text { Percentual de bolsas ofertadas } \\
\text { em relação aos inscritos }\end{array}$ \\
\hline 2005 & 422.531 & 112.275 & 26,6 \\
2006 & 994.405 & 138.668 & 13,9 \\
\hline & & 24,5 \\
2007 & 668.561 & 163.854 & 21,1 \\
2008 & 1.063 .915 & 225.005 & 25 \\
2010 & 989.078 & 247.643 & 17 \\
2011 & 1.410 .266 & 240.441 & 12,8 \\
2012 & 1.990 .044 & 254.598 & 17,1 \\
\hline 2013 & 1.665 .371 & 284.622 & 17,2 \\
\hline TOTAIS & 1.469 .814 & 252.374 & $\mathbf{1 8}$ \\
\hline
\end{tabular}

Observe que o percentual de bolsas ofertadas em relação ao número de inscritos, em todos dos anos esteve abaixo de $27 \%$ e em relação ao total de inscritos e o total de bolsas ofertadas esse percentual ficou em, 18\%. Deste modo percebe-se que a concorrência é expressiva, e que os candidatos que não foram beneficiados tentam uma nova chance e a nova tentativa inicia-se em melhorar a nota do ENEM, visto que é a nota do exame que seleciona os candidatos, segundo informa o site o MEC. É necessária uma nota maior de 450 pontos na prova objetiva e maior que zero na redação para concorrer à bolsa.

Um candidato à bolsa do ProUni precisa passar por três processos seletivos, inicialmente pelo ENEM, a seleção para a Instituição de Ensino Superior Privada a qual optou, pois muito candidatos concorrem a mesma vaga, por fim, a seleção para a bolsa do programa. Sendo assim, durante os processos o estudante disputa o mérito da sua 
vaga com dezenas, centenas ou milhares de outras pessoas, que assim como ele buscam o acesso ao Ensino Superior. Ao contrário do senso-comum, o ProUni se coloca como uma forma meritocrática de acesso ao Ensino Superior.

Para uma melhor compreensão da importância do Ensino Superior no país, a tabela 2 demonstra os totais e a evolução do número de matrículas por grau acadêmico de 2001 a 2010.

Tabela 2 - Evolução do Número de Matrículas por Grau Acadêmico - Brasil - 2001-2012

\begin{tabular}{cccccccc}
\hline Ano & Total & Bacharelado & $\begin{array}{c}\text { Bacharelado e } \\
\text { Licenciatura }\end{array}$ & Licenciatura & Tecnológico & $\begin{array}{c}\text { Não } \\
\text { Informado }\end{array}$ & $\begin{array}{c}\text { Não } \\
\text { Aplicável }\end{array}$ \\
\hline $\mathbf{2 0 0 1}$ & 3.036 .113 & 2.036 .724 & 279.356 & 648.666 & 69.797 & 1.570 & $\ldots$ \\
$\mathbf{2 0 0 2}$ & 3.520 .627 & 2.340 .407 & 306.465 & 789.575 & 81.348 & 2.832 & $\ldots$ \\
$\mathbf{2 0 0 3}$ & 3.936 .933 & 2.600 .193 & 332.885 & 885.384 & 114.770 & 3.701 & $\ldots$ \\
$\mathbf{2 0 0 4}$ & 4.223 .344 & 2.788 .406 & 344.570 & 928.599 & 158.916 & 2.853 & $\ldots$ \\
\hline $\mathbf{2 0 0 5}$ & 4.567 .798 & 3.001 .095 & 356.605 & 970.331 & 237.066 & 2.701 & $\ldots$ \\
$\mathbf{2 0 0 6}$ & 4.883 .852 & 3.172 .626 & 361.093 & 1.023 .582 & 325.901 & 650 & $\ldots$ \\
\hline $\mathbf{2 0 0 7}$ & 5.250 .147 & 3.419 .495 & 345.778 & 1.062 .073 & 414.822 & 7.979 & $\ldots$ \\
\hline $\mathbf{2 0 0 8}$ & 5.808 .017 & 3.772 .939 & 333.024 & 1.159 .750 & 539.651 & 2.653 & $\ldots$ \\
\hline $\mathbf{2 0 0 9}$ & 5.954 .021 & 3.867 .551 & 214.028 & 1.191 .763 & 680.679 & $\ldots$ & $\ldots$ \\
\hline $\mathbf{2 0 1 0}$ & 6.379 .299 & 4.226 .717 & $\ldots$ & 1.354 .989 & 781.609 & $\ldots$ & 15.984 \\
\hline $\mathbf{2 0 1 1}$ & 5.746 .762 & 4.196 .423 & $\ldots$ & 926.780 & 606.564 & $\ldots$ & 16.995 \\
\hline $\mathbf{2 0 1 2}$ & 5.923 .838 & 4.344 .030 & $\ldots$ & 916.593 & 640.683 & $\ldots$ & 22.532 \\
\hline
\end{tabular}

Fonte: Censo da Educação Superior, 2012.

Através da tabela 2, verifica-se que de 2001 a 2010 o número total de matrículas dobrou, em 2011 houve uma queda, levemente recuperada em 2012, mas que não se iguala ou é superior ao número de matrículas em 2010, que foi o maior no período de 2001 a 2013.

Um ponto interessante é cruzarmos o número de matrículas com o número total de matrículas com a relação de beneficiados do Pro Uni. Para tanto, foi elaborada a tabela 3 com esse propósito: 
Tabela 3 - Número de matrículas versus Beneficiados Pro Uni de 2005 a 2012

\begin{tabular}{cccc}
\hline Ano & Matrículas & Beneficiados & $\begin{array}{c}\text { \% Beneficiados em relação ao } \\
\text { número de Matrículas }\end{array}$ \\
\hline $\mathbf{2 0 0 5}$ & 4.567 .798 & 112.275 & 2,46 \\
$\mathbf{2 0 0 6}$ & 4.883 .852 & 138.668 & 2,84 \\
$\mathbf{2 0 0 7}$ & 5.250 .147 & 163.854 & 3,12 \\
$\mathbf{2 0 0 8}$ & 5.808 .017 & 225.005 & 3,87 \\
$\mathbf{2 0 0 9}$ & 5.954 .021 & 247.643 & 4,16 \\
$\mathbf{2 0 1 0}$ & 6.379 .299 & 240.441 & 3,77 \\
$\mathbf{2 0 1 1}$ & 5.746 .762 & 254.598 & 4,43 \\
$\mathbf{2 0 1 2}$ & 5.923 .838 & 284.622 & 4,80 \\
\hline TOTAL & 44.513 .734 & 1.667 .106 & 29,45 \\
\hline
\end{tabular}

Fonte: Censo da Educação Superior, 2012 e MEC, 2014.

Dentro do período temporal (2005-2012) verificado na tabela 3, nota-se que o percentual de beneficiados ProUni em relação ao número de matriculados no Ensino Superior ainda é pequeno. Frente ao número de matrículas, assim como o número de inscritos até se chegar a ser um bolsista de fato, nota-se um longo caminho a percorrer para aqueles que almejam ingressar nesse nível de ensino via o Programa.

Através do exemplo do Pro Uni, verifica-se a base meritocrática que perpassa todo o processo seletivo do programa. Podemos incluir nesse âmbito, que o aluno precisa se empenhar nos estudos na Educação Básica para conseguir uma boa nota no ENEM. A nota obtida nessa prova se coloca como o resultado do mérito do aluno, agregando obviamente toda a problematização do ensino público e privado, demonstrando que por trás desta nota existe a subjetividade excluída pela objetividade das notas e estatísticas.

\section{CONSIDERAÇÕES FINAIS}

Entendendo a meritocracia como uma forma de reconhecimento, analisadas aqui no âmbito da Educação e da Administração, se percebe a prática meritocrática comum nas empresas e ainda de maneira tímida na Educação. Tímida, pois, o tema sofre resistências no meio da educação, por entender um viés capitalista em sua essência, apesar dos pressupostos de igualdade de oportunidades como base meritocrática. No entanto, propõe-se ao leitor a seguinte questão para reflexão: a iniciativa da utilização da meritocracia na educação poderia ter como exemplo a sólida experiência das empresas? Talvez. 
O tema não é novo na educação, mas tem sido discutido e experimentado, a exemplo do Estado de São Paulo, que institui o Programa de Valorização pelo Mérito para professores, supervisores e diretores da rede estadual de ensino. Ao apresentar as semelhanças e diferenças da meritocracia sob a ótica da Educação e da Administração, percebeu-se semelhanças em maior parte, como visto no quadro 1.

O conceito de Meritocracia na Educação e na Administração, destaca a meritocracia como o reconhecimento a partir do igualitarismo e da justiça. Isso significa dizer que: para que um indivíduo seja reconhecido dentro de um processo justo e igualitário, os melhores sejam mesmo os melhores com as mesmas oportunidades. Já as diferenças, em minoria, destacam no âmbito da Administração a naturalidade do processo como meio de reconhecimento profissional e consequentemente financeiro do indivíduo na organização. No âmbito da Educação se destaca a resistência à mudança, ao desafio de um trabalho reconhecido pelo mérito.

Tão natural para uns, tão difícil para outros. Conseguirá a Educação mobilizar os atores envolvidos para a implantação do trabalho meritocrático? De que forma a Administração pode contribuir? Talvez, para tal, se faça necessário unir as competências e experiências de ambas às áreas de modo que se fortaleçam enquanto expectativa de desenvolvimento. Embora os contextos sejam diferentes, em ambos, há necessidade de pessoas comprometidas de modo a melhor desenvolver o que nelas é proposto.

\section{REFERÊNCIAS}

BARBOSA, Lívia. "Meritocracia à brasileira: o que é desempenho no Brasil". Revista do Serviço Público. Brasília, n. 3, volume 120, ano 47, 1996. Endereço:

<http://seer.enap.gov.br/index.php/RSP/article/download/396/402> [07 jun. 2014].

Lívia. Igualdade e meritocracia: a ética do desempenho nas sociedades modernas. Rio de Janeiro, Editora FGV, 2006.

BRASIL. Constituição da República Federativa do Brasil de 05 de outubro de 1988. Endereço: <http://www.planalto.gov.br/ccivil_03/constituicao/constituicao.htm> [11 jun. 2014].

Lei $\mathbf{n}^{\circ} 9.394$ de 20 de dezembro de 1996. Endereço:

$<$ http://portal.mec.gov.br/arquivos/pdf/ldb.pdf > [11 jun. 2014].

CHIAVENATO, Idalberto. Administração nos Novos Tempos. Rio de Janeiro, Elsevier, 2010. 
DUBET, François. “O que é uma escola justa?”. Cadernos de Pesquisa. Brasília, n. 123, volume 34, 2004. Endereço:

<http://www.scielo.br/pdf/cp/v34n123/a02v34123.pdf> [08 jun. 2014].

FELICETTI, Vera Lucia; MOROSINI, Marília Costa. "Equidade e iniquidade no Ensino Superior: uma reflexão?” Ensaio: aval. pol. públ. Educ. Rio de Janeiro, n. 62, volume 17, 2009. Endereço: 〈http://www.scielo.br/pdf/ensaio/v17n62/a02v1762.pdf> [10 ago. 2014].

MEC. Ministério da Educação. O programa. Endereço:

$<$ http://prouniportal.mec.gov.br/index.php?option=com_content $\&$ view=article\&id=124 \&Itemid=140> [28 mai. 2014].

PRIBERAM Dicionário. Endereço:<http://www.priberam.pt/dlpo/ [28 mai. 2014].

ROBBINS, Stephen P.; Timothy, Judge A.; Sobral, Filipe. Comportamento

Organizacional, teoria e prática no contexto brasileiro. São Paulo, Pearson, 2010.

ROCHA NETO, Ivan. Gestão Estratégica de conhecimentos \& competências: administrando incertezas e inovações. Brasília, ABIPTI, UCB/Universa, 2003.

SÃO PAULO. Secretaria da Educação do Estado de São Paulo: Serra sanciona lei da Valorização pelo Mérito para professores do Estado. Endereço:

$<$ http://www.educacao.sp.gov.br/noticias/serra-sanciona-lei-da-valorizacao-pelo-meritopara-professores-do-estado> [11 jun. 2014].

VALE, Ione Ribeiro; Ruschel, Elizete. "Política educacional brasileira e catarinense (1934-1996): uma inspiração meritocrática". Revista Electrónica de Investigación y Docencia (REID), 2010 (p. 73-92). Endereço:

<http://www.ujaen.es/revista/reid/revista/n3/REID3art4.pdf> [11 jun. 2014]. 